\title{
STRAIN ANALYSIS ON THE MICRO-NANO-SCALE EMBEDDED ASPERITIES IN THE GRINDING PROCESS
}

\author{
Lianfeng Lai, Chenhui Gao, Jianmeng Huang
}

Original scientific paper

A two-dimensional micro-nano grinding model with the fractal surface is constructed, which considers the wear-out failures of the materials and the adhesive effects in the contact process. Also, the strain changes of the asperity during the grinding are dynamically discussed. The finite element method is employed to simulate the strain field in the process of grinding. It is indicated that the larger the interfacial shear strength is, at the same grinding distance, the greater its equivalent plastic strain is, the easier the rough solid is prone to wear and tear. The maximum point of the plastic deformation determines the first place where the first cracks occur, either on the surface or at a certain distance from the surface. Also, the larger the normal evendistributed load is, the larger the maximum plastic deformation of the asperity at the initial contact time is, which determines an earlier occurrence time of the initial cracks. Furthermore, the greater the grinding rate is, the longer the distance that two interactively contacting asperities start to wear is. By studying the distribution of the strain field of the embedded asperities, the real causes why the materials are ground and worn at the scale of micro-nano are explored.

Keywords: fractal; grinding; interfacial shear strength; strain; wear

\section{Analiza deformacije hrapavosti u mikro-nano mjerilu u postupku brušenja}

Izvorni znanstveni članak

Konstruiran je mikro-nano model za brušenje s fraktalnom površinom, kojim se razmatraju oštećenja materijala zbog istrošenosti i adhezivni učinci u postupku dodira. Dinamički se razmatraju i promjene u deformaciji hrapavosti tijekom brušenja. Za simuliranje područja deformacije u postupku brušenja primijenjena je metoda konačnih elemenata. Pokazano je da što je veća smična čvrstoća na graničnoj površini na istoj udaljenosti brušenja, to je veća ekvivalentna plastična deformacija, a gruba površina se lakše izlaže trošenju i kidanju. Maksimalna točka plastične deformacije određuje početno mjesto pojave pukotine, bilo na površini ili na nekoj udaljenosti od površine. Isto tako, što je veće jednako raspoređeno normalno opterećenje, to je veća maksimalna plastična deformacija hrapavosti na početku dodira, a to određuje i raniju pojavu inicijalnih pukotina. Nadalje, što je veća brzina brušenja, to je veća udaljenost na kojoj se dvije interaktivne dodirne površine počinju trošiti. Analizirajući raspodjelu područja deformacije ugrađene hrapavosti, istražuju se stvarni uzroci brušenja i trošenja materijala u mikro-nano mjerilu.

Ključne riječi: brušenje; deformacija; fraktal; smična čvrstoća na graničnoj površini; trošenje

\section{Introduction}

With the expansion of living space and convenience movement, the application range of micro products expands rapidly, and they are now widely used in national defence, aerospace, measurement and detection, biomedicine, electronics and computer science, instrumentation and other fields. Since the $21^{\text {st }}$ century, under the drive of fierce market competition, the micromanufacturing technology has become one of the key development directions and gained intense attention from the countries with highly developed manufacturing industry. Academician Yang Shuzi proposed that the extensive use of microsystem and micro-manufacturing products would trigger a new influential technological revolution to the world, just like the microelectronic technology. And this is a high-tech challenge and an opportunity that might become a high-tech breakthrough for China to catch up with the advanced world level [1].

The theoretical basis of micromachining technology is the issue of friction and wear. The two rough surfaces in the friction process are in contact, with features like dynamic changes and randomness. By means of experimental measures, it is quite difficult to observe and analyse the frictional contact surface in a direct and dynamic way. Thus, the current research on the contact state of the friction surface mainly focuses on the establishment of the reasonable theoretical model for the analysis. Also, the study simulates or emulates the friction phenomena and processes via computer, which acts as the tool to explore the mechanism and the pattern of the tribology together with the experimental study. Besides, simulation is able to provide predictions for tribology behaviours, such as stress, temperature, the amount of wear and its life expectancy, so as to guide the tribology design as an important basis for the project, but also to deepen their understanding of the physical image of the friction and wear processes.

The study on the static contact on the double rough surface and the grinding process has made some progress [2-3], some of which involves adhesion contact. Komvopoulos et al. [4] have established a threedimensional fractal rough surface, considered the adhesion impact among the contact interfaces under the action of the normal load, and analysed the changes in the relationship among the full plastic deformation, the wear rates and the frictional coefficients of the asperities, with three different friction pairs in different adhesion conditions (vacuum, purified air, poor lubrication, normal lubrication and favourable lubrication) by means of the analytic method. Ge Shirong [5] and others researchers have started from the analysis of contact mechanics and kinematics on one pair of asperities, established the relationship between the sliding frictional resistance and the contact states of the rough surface under the condition of non-hydrodynamic lubrication. Based on the fractal geometry theory, the sliding friction fractal prediction model is deduced, and the correctness of the model is theoretically analysed. Sahoo et al. [6] have studied the adhesive wear behaviour among the fractal rough surfaces under the action of low loads. Yang et al. [7] have analysed the impact of the changes of three parameters, 
including the normal load, the fractal parameter and the interfacial shear strength, on the friction coefficients by means of the analytical method.

Rough surface is composed of a series of asperities with different curvature radiuses. Thus, this paper establishes the micro-nano-scale double rough surface grinding model, makes comprehensive consideration of the impact of the interaction among the asperities, the adhesive forces of the grinding process, the wear and tear among the asperity and the like, and analyses the strain variation of the embedded asperities during grinding by the finite element software (ABAQUS).

\section{The establishment of two-dimensional double rough fractal grinding model}

From the microscopic point of view, the contact between the rough surfaces occurs among a series of asperities, and the contact is featured with unevenness. Fractal theory is used to analyse, evaluate and model the surface appearance, which is able to provide the features of surface appearance on all scales and to accurately simulate the real rough surface [8]. Based on the previous research on the rough fractal surface and the sliding plane model [9], this paper establishes the double rough fractal surface grinding model and considers the impact of material wear and adhesive force of contact interface in the grinding process. The process of grinding the double rough surface involves the contact analysis, the continuation of the sliding, the elastic-plastic deformation and the hardening of the materials, the impact of frictional heat, adhesion and fracture of the material micro-area, etc. A number of nonlinear problems are concerned, and it is complicated to establish the physical model and the mathematical model. Thus, when the microscopic dynamics model is established in the grinding process, the crown-down approach is adopted for the study, extending from simple to complex, from the single asperity to the multiple asperities contact, and from two-dimensional to three-dimensional model.

\subsection{The establishment of the fractal profile of rough surface}

Due to the presence of surface roughness, the contact between two surfaces occurs in the discrete asperities. Thus, the actual contact area is only a small part of the nominal contact area, which brings difficulty to the master of surface contact properties and stress distribution, as well as the carrying capacity of the friction pair. To calculate the actual contact area and to predict how the contact area changes with the loads, the traditional research simplifies the asperities on the contact surface as sphere, spheroid, cylinder, sinusoidal corrugation, rhomboid, cone, pyramid, or other ideally smooth geometries, and the asperity distribution is simplified as ones with equal altitudes or the Gauss distribution. Since the traditional simplified model for the surface morphology is too simple, it does not reflect the unsteady stochastic characteristics and the multiple scale characteristic of the roughness, and the predictions of the resulting contact model are not unique [10]. Objective and accurate representation of the rough surface is an important condition of tribology. The study indicates that, when the microscopic contour line of the rough surface in Fig. 1 is repeatedly amplified, it is possible to observe a detail that the micro-nano or even smaller roughness increases. Also, it is observed that the roughness profile structure at different magnifications is very similar, indicating the self-similarity of the rough surface at different scales may be exclusive and determined, and this feature is characterized by the fractal geometry [11]. In tribology, the Fractional Brownian Motion (FBM) is generally used as the mathematical model of the rough surface fractal modelling.

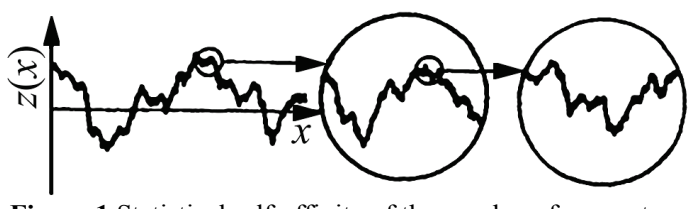

Figure 1 Statistical self-affinity of the rough surface contour

The fractal surface or the contour synthesized on the basis of FBM has been widely used in the tribology research. A number of algorithms are used to synthesize FBM fractal contour or surface in the computer, such as the Poisson step method, the random midpoint displacement (RMD) method, the successive random addition method, the discrete Fourier transform (DFT) method, the Weierstrass-Mandelbrot (WM) function method, the fractal interpolation simulation method, the time series simulation method, and the wavelet transform method [12]. The Weierstrass-Mandelbrot (shortly referred to as the $\mathrm{W}-\mathrm{M}$ ) fractal function adopts the explicit function to express the fractal surface, and the modelling algorithm is simply achieved, which thus has become one of main modelling algorithms for the fractal surface in the study of tribology.

The geometrical appearance of the rough surface is very complex. Based on the contact mechanics, the elastic-plastic mechanics, the heat transfer theory and other elementary theories, it is rather difficult to conduct in-depth theoretical analysis in order to obtain the theoretical solution of the tribological problem. A number of current researches is still conducted based on the twodimensional contour of the surface. Therefore, this paper uses the univariate Weierstrass-Mandelbrot fractal function [13] to synthesize the fractal contour of the rough surface.

$$
z(x)=L\left(\frac{G}{L}\right)^{(D-1)} \sum_{n=0}^{\infty} \frac{\cos \left[2 \pi \gamma^{n}(x / L)+\phi_{n}\right]}{\gamma^{(2-D) n}}
$$

In the formula, $L$ is the sampling length; $G$ is the frequency-independent scale coefficient; $\varphi_{n}$ represents the uniformly distributed random phase; $D$ stands for the fractal dimension $(1<D<2) ; \gamma$ represents the scale coefficient $(\gamma>1) ; \gamma^{n}$ represents the frequency, and $n$ is the frequency coefficient.

The related parameters of the fractal function are given. Matlab is used to obtain the point cloud of the fractal contour, then the spline curve in the Pro/e is applied to realize the simulation of the fractal contour, 
and the rough surface is constructed by operation. Fig. 2 illustrates the rough surface model with a fractal contour.

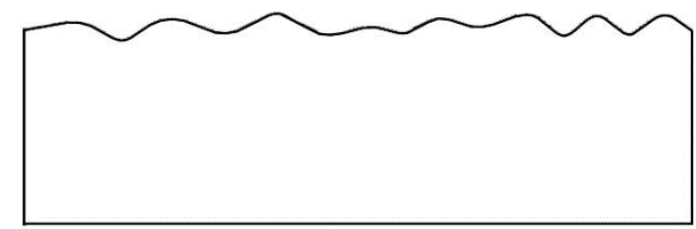

Figure 2 The two-dimensional rough surface with a fractal contour

\subsection{The establishment of the two-dimensional double rough grinding model}

In the past contact mechanics analysis on the fractal surface, one of the contact surfaces is assumed to be flat, and the normal contact points of all the asperities are perpendicular to the global $X$ direction. However, there generally exists a contact angle $\theta$ between the surfaces of the actual rough solid. Therefore, in order to study the grinding process that is more in line with the actual state, the paper establishes a grinding model for the rough twodimensional surface.

In the grinding process, wear and friction as well as the changes of force mainly occur on the surface of the components of the friction pair. Thus, the grinding geometry model of rough solid A and rough solid B is established to replace the grinding frictional process of the entire friction pair component. Due to the need for process analysis, according to the rough surface of the fractal contour in Fig. 2, a three-dimensional solid with a unit thickness of 1 and the same sectional profile is constructed, which is simplified as two-dimensional considerations. The established geometry and boundary conditions are shown in Fig. 3.

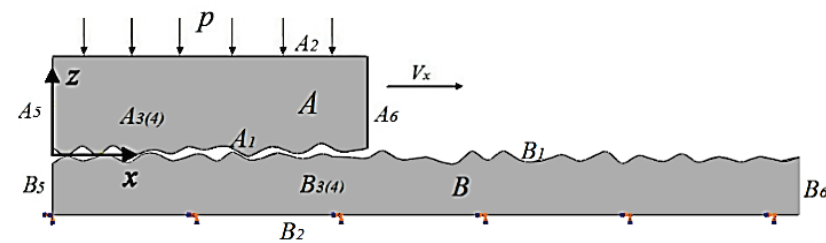

Figure 3 Schematic illustration of the boundary conditions for the model

In Fig. 3, A represents the upper rough solid, and B represents the lower rough solid. The issue is that the established three-dimensional solid model is simplified as the two-dimensional plane strain, so fixed constraint is applied on the front and rear of the symmetry plane $\left(A_{3}\right.$, $A_{4}$ and $\left.B_{3}, B_{4}\right)$ at the Y-direction. In the initial state, the two rough solids $\mathrm{A}$ and $\mathrm{B}$ zero make zero-gap contact with each other. In the loading process, an external applied load with even-distributed pressure is applied on the upper surface of rough solid $\mathrm{A}\left(A_{2}\right)$ in the $\mathrm{Z}$ direction, and rough solid $B$ stays immovable. In the grinding process, constraints are imposed on rough solid A on each direction in a rotating way. A constant velocity $v$ is applied on the acting surface $\left(A_{5}\right)$ and is parallel ground along the $x$ direction, namely, rough solid $\mathrm{A}$ is subject to a changing thrust $F_{1}$ in the $x$ direction. The specific boundary conditions are:

$$
\begin{gathered}
\left\{\begin{array}{cc}
\sigma_{z}=P & \text { surface } A_{2} \\
M_{y}=0 & \text { surface } A_{5}, A_{6} \\
u_{y}=M_{x}=M_{z}=0 & \text { surface } A_{3}, A_{4} \\
v_{x}=V & \text { surface } A_{5}
\end{array}\right. \\
\left\{\begin{array}{cc}
u_{x}=P & \text { surface } B_{2} \\
u_{y}=0 & \text { surface } B_{2} \\
u_{z}=0 & \text { surface } B_{2} \\
u_{y}=M_{x}=M_{z}=0 & \text { surface } B_{3}, B_{4}
\end{array}\right.
\end{gathered}
$$

\subsection{The establishment of the finite element model}

In the process of establishing the finite element model, a vitally important process is to divide the mesh, which is completed on the basis of a variety of experiences and skills as needed. Since the achievement of smooth, fast and accurate analysis is directly related to the quality of the mesh, a favourable grid consists of three elements:

1) the appropriate element type

2) the favourable element shape

3) the appropriate mesh density.

The friction between the two opposing grinding solid surfaces is related to the interactive action of the contact surface. To divide the significant areas into smaller meshes, the segmentation technique is applied to cut the component into two parts - the surface area and the nonsurface area. The surface area is divided into smaller meshes, and the non-surface area is divided into larger meshes, to reduce the number of overall meshes and the computation time. Fig. 4 is the division diagram of the finite element mesh.

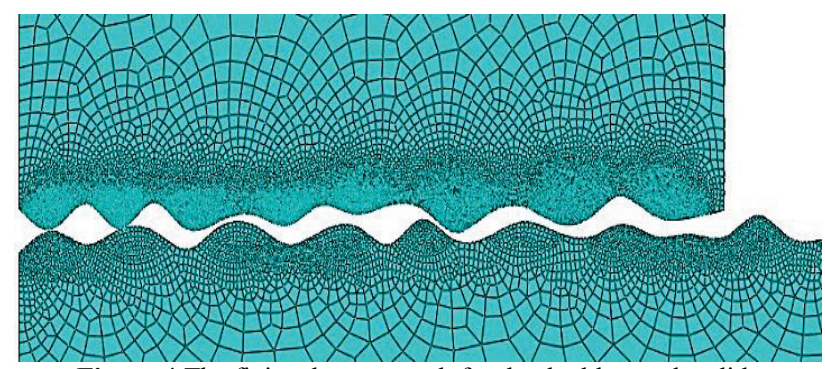

Figure 4 The finite element mesh for the double rough solids

\subsubsection{Loading form of grinding process}

The loading process in this paper is divided into two periods. Within the first period, a normal even-distributed load is pressed on the upper surface $A_{2}$ of rough solid $A$, increasing from zero to the maximum value. And contact deformation occurs to the upper and lower rough solids, and the two rough solids make full contact and reach the state of equilibrium. During the second period, the normal load remains unchanged, and a constant horizontal velocity is applied on rough solid $A$, so that rough solid $A$ makes linear grinding on rough solid B in the horizontal direction. The grinding speed experiences a smooth transition, increasing from the initial value of zero to the maximum value, and the applied horizontal grinding speed is maintained unchanged until the end of the slide. 


\subsubsection{The consideration of the factor of contact interface adhesion}

Under the action of load, the contact pressure of various local contact points of the two rough surfaces is extremely large, so that the atoms within the two objects are close enough to create adhesion. As shown by the solid state physics theory, when adhesion occurs, according to the Lennard-Jones potential function, the contact adhesion stress $\sigma_{n}$ is as follows:

$$
\sigma_{n}=\frac{8 W_{a b}}{3 z_{0}}\left[\left(\frac{z}{z_{0}}\right)^{-3}-\left(\frac{z}{z_{0}}\right)^{-9}\right]
$$

wherein, $z$ is the distance between the two atom interfaces. $z_{0}$ is the balance distance between the atoms. $W_{a b}$ is the total surface energy of the adhesion points in the localized contact area, and $W_{a b}=\gamma_{a}+\gamma_{b}-\gamma_{a b}$. In the formula, $\gamma_{a}$ and $\gamma_{b}$ are respectively surface free energy of the two contact surfaces. $\gamma_{a b}$ is the free energy existing on the surface. However, due to the current lack of suitable direct measurement method for $W_{a b}$ or $\gamma_{a b}$, the approximate method is used in practice. According to the frictional adhesion theory proposed by Bowden and Tabor, large pressure exists on the actual contact point of the occurrence nodes and the welding places. And a fixed shear strength $\tau$ on the rough interface is given to represent the adhesive stresses of contact nodes.

In the friction and grinding process, the contact conditions of the rough surface are divided into adhesion and shear sliding. The shear is then divided into shear on the interface and shear inside the metal (generally the inside of softer metals):

(1) Adhesion: $\bar{\tau}<\bar{\tau}_{\text {node }} \leq k$

(2) Sliding:

1) shear of the adhesive interface: $\bar{\tau}_{\text {node }}<\bar{\tau}<k$

2) shear occurs inside the metal: $k<\bar{\tau}<\bar{\tau}_{\text {node }}$

In the formula, $\bar{\tau}$ is the equivalent shear stress between the two rough solids. $\bar{\tau}_{\text {node }}$ is the equivalent shear strength of the interfacial adhesion junction. $k$ is the shear strength of the material $\left(k=\sigma_{y} / \sqrt{3}\right)$.

\section{The determination of model parameters \\ 3.1 The determination of model parameters}

Titanium alloy [14] (Ti-6Al-4V) holds high strength, light weight, favourable corrosion resistance and other characteristics, and is commonly used in aviation, aerospace and other fields. It is listed as one important strategic material, and is significant in analysing its friction and wear properties. Therefore, this paper applies titanium alloy as the sample slide. Along with the plate specimen GCr15 of the friction and wear tester, the two of them comprise the friction pair. DCS-200 computercontrolled electronic universal testing machine is adopted to conduct compress experiments on the materials. The yield stress of Ti-6Al-4V $\sigma_{y}=1000 \mathrm{MPa}$. The yield stress of GCr15 $\sigma_{y}=1700 \mathrm{MPa}$. The Johnson-Cook model is used for the failure criterion of materials [15]. The stressstrain curves are shown in Fig. 5.

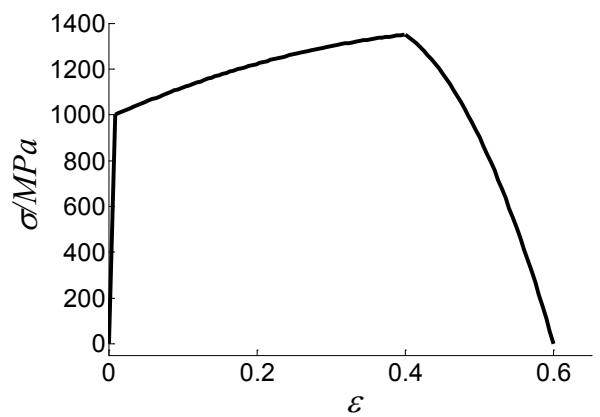

(a) Ti-6Al-4V

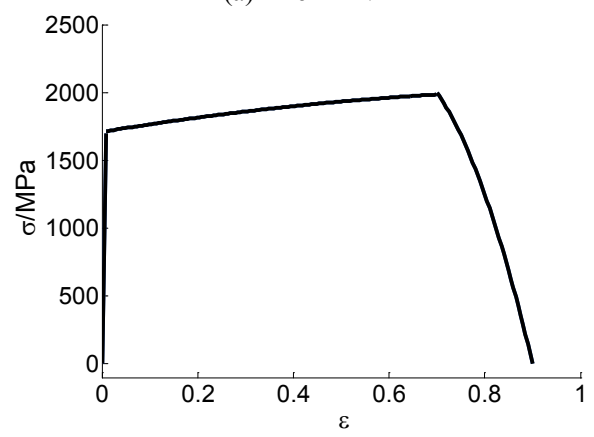

(b) $\mathrm{GCr} 15$

Figure 5 The $\sigma-\varepsilon$ graph of the frictional auxiliary material

Table 1 Mechanical properties of the contact auxiliary materials [16]

\begin{tabular}{|c|c|c|}
\hline $\begin{array}{c}\text { Friction auxiliary } \\
\text { materials }\end{array}$ & $\begin{array}{c}\text { Elastic modulus } \\
E(\mathrm{GPa})\end{array}$ & $\begin{array}{c}\text { Poisson's ratio } \\
v\end{array}$ \\
\hline Ti-6Al-4V & 115 & 0.31 \\
\hline GCr15 & 198 & 0.26 \\
\hline
\end{tabular}

\subsection{The determination of rough surface parameters}

The parameter range of the common roughness on the engineering surface is $R z=0.1 \div 50 \mu \mathrm{m}$. In this paper, by the application of XSG-type double tube microscope, the ten points height of microcosmic irregularities of the nonrunning- in titanium solid is measured as $R z=23.3142$ $\mu \mathrm{m}$. According to the aforementioned simulation method of the rough surface, based on the consideration of surface evenness and frequency distribution density (actually a series of cosine functional superposition), $\gamma=1.513$. As indicated by the analysis on the sample surface profile in the experiments, through power spectrum transform, the fractal dimension of the corresponding surface is $D=1.5$. According to the simulation method of the rough surface, based on the consideration of surface evenness and frequency distribution density, it is determined that the related parameter of the fractal functions-scale coefficient $G=3.0 \mu \mathrm{m}$, and the sampling length is $L=$ $L s \times(N-1)=24 \times(60-1)=1416 \mu \mathrm{m}$.

According to the W-M fractal function, the MATLAB self-programming is used to simulate the rough surface, and to calculate the ten points average height of microcosmic irregularities of this simulated rough surface $R z=23.1175 \mu \mathrm{m}$, which approximates the experimental measured values. Thus, it is used to characterize the actual rough engineering surface. For the other rough solid GCr15 of the friction pair, since the impact of fractal parameters on the grinding process is not 
considered, the same fractal parameters are used to construct the rough surface.

\subsection{The selection of contact parameters}

By changing three factors - the normal load, the interfacial shear strength and the grinding speed, this paper analyses the wear rate, contact area, friction and other variation patterns in the double rough surface grinding process. The specific parameters are as follows:

1) Change the normal even-distributed load applied on rough solid $\mathrm{A}$.

2) Change the value of shear strength $\tau$ that is required to separate the contact surfaces of the upper and lower rough solids after the interfacial adhesion (referred to as the interfacial shear strength). In other words, changing the interfacial shear strength value is actually changing the contact conditions between the rough surfaces (ambient environment, lubrication state, the friction surface condition, etc.). In [7] the authors show three conditions are respectively selected for analysis. $\tau=$ $0.2 k$ represents the operating condition of boundary lubrication; $\tau=0.8 k$ represents the operating condition of non-lubrication; $\tau=k$ is the maximum shear strength of the materials.

3) change the value of the horizontal grinding speed $v$ on the solid rough A.

The specific parameters are illustrated in Tab. 2 .

Table 2 Different parameters of the finite element simulation

\begin{tabular}{|c|c|c|c|c|c|c|c|c|c|}
\hline \multirow{2}{*}{$p, \tau(\mathrm{MPa})$} & \multicolumn{9}{|c|}{$v(\mathrm{~m} / \mathrm{s})$} \\
\hline & \multicolumn{3}{|c|}{20} & \multicolumn{3}{|c|}{30} & \multicolumn{3}{|c|}{60} \\
\hline 20 & - & - & - & - & $0.8 k$ & - & - & - & - \\
\hline 40 & - & $0.8 k$ & - & $0.2 k$ & $0.8 k$ & $k$ & - & $0.8 k$ & \\
\hline 60 & - & - & - & - & $0.8 k$ & - & - & - & - \\
\hline
\end{tabular}

\section{Results and discussion}

When the two metal surfaces make contact and relative displacements, if a small stress within the elasticity limit is applied to the interior of the object, some traces would be left, and traces of this kind would add up to form wear. The wear is a process of plastic deformation and fracture of the surface and the subsurface materials. Generally speaking, it should include the local accumulation of plastic deformation, the formation and propagation of micro-crack, combination until material separation and other processes. The grinding process between the double rough surfaces is essentially an interactive process between the asperities. Thus, this paper conducts analysis and study on the equivalent plastic strain process of the asperities under different contact conditions. Fig. 6 is the distribution diagram of the asperity contact pair on the twodimensional double tough surface.

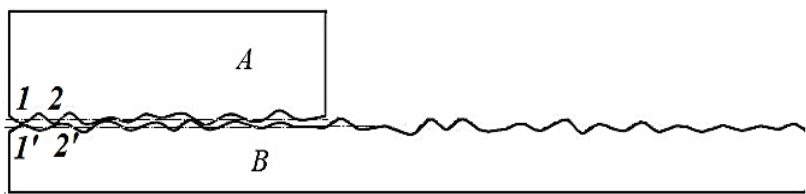

Figure 6 The distribution diagram of i1 and i2 on the asperity contact

\subsection{Effects of the shear strength on the equivalent plastic strain distribution}

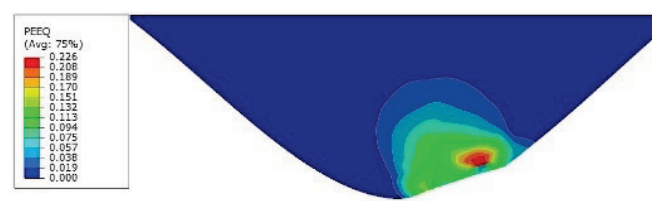

(a) $t=0 \mu \mathrm{s}$

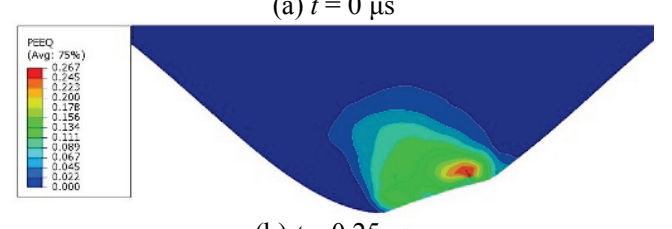

(b) $t=0.25 \mu \mathrm{s}$

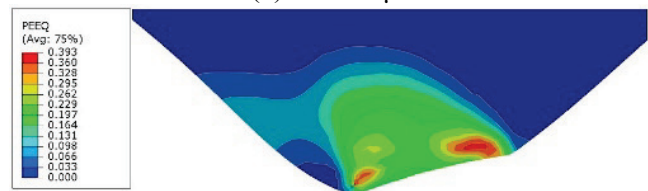

(c) $t=0.5 \mu \mathrm{s}$

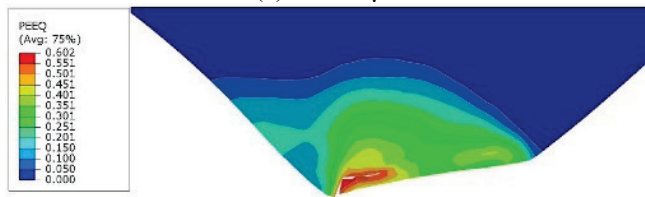

(d) $t=0.73 \mu \mathrm{s}$

Figure 7 Contour plots of the equivalent plastic strain of the asperity at different grinding moments, with shear strength of $0.2 k$

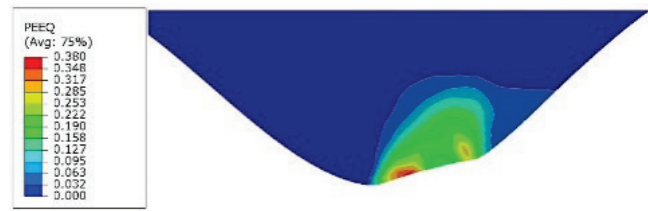

(a) $t=0 \mu \mathrm{s}$

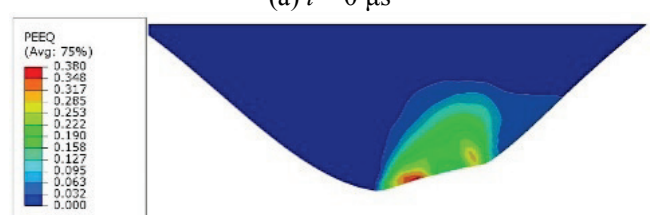

(b) $t=0.1 \mu \mathrm{s}$

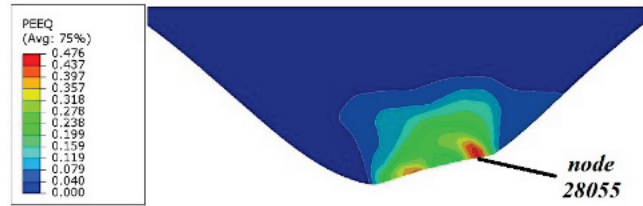

(c) $t=0.24 \mu \mathrm{s}$

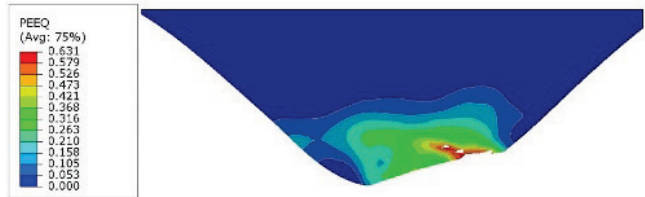

(d) $t=0.3 \mu \mathrm{s}$

Figure 8 Contour plots of the equivalent plastic strain of the asperity at different grinding moments, with shear strength of $0.8 \mathrm{k}$

Figs. 7, 8 and 9 respectively represent the contour plots of the equivalent plastic strain before the wear of the asperity No. 2 at different grinding moments under different shear strength.

As indicated in Figs. 7, 8 and 9, the grinding process of the asperity is as follows. Two rough surfaces make contact with each other under the normal load. After the asperity with a higher part makes contact, the elastic 
deformation occurs until the plastic deformation. As the load continues to increase, the contact surface of the asperity and the interior of plastic deformation continuously keep upward. The maximum amount of plastic deformation occurs at the contact surface, or at a certain level of the asperity, as shown in Figs. 7(a), 8(a) and 9(a). With the application of the grinding speed, relative displacement and slide occurs between the two contact asperities. The double rough surfaces make contact with each other and produce canines mosaic, in this case, the ongoing grinding should be guaranteed. Thus, the asperities of one surface move upward along the asperities of another surface and apply work, or the asperities deform, wear or break, as shown in Figs. 7(d), $8(d)$ and 9(d). With the combined action of the normal force and the tangential force, the plastic damage accumulates until the limit of plastic deformation of the materials, resulting in the formation of cracks and the extension until the formation of wear debris falling.

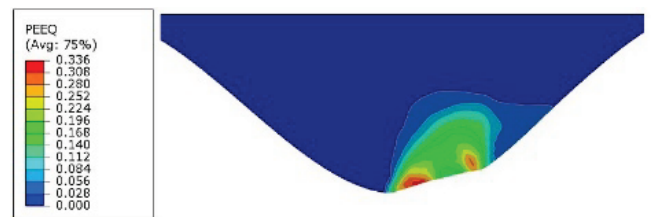

(a) $t=0 \mu \mathrm{s}$

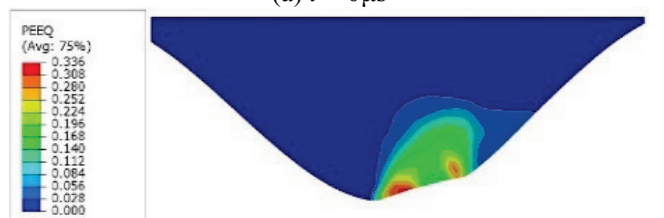

(b) $t=0.1 \mu \mathrm{s}$

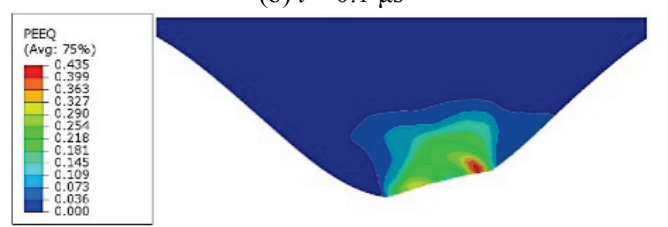

(c) $t=0.2 \mu \mathrm{s}$

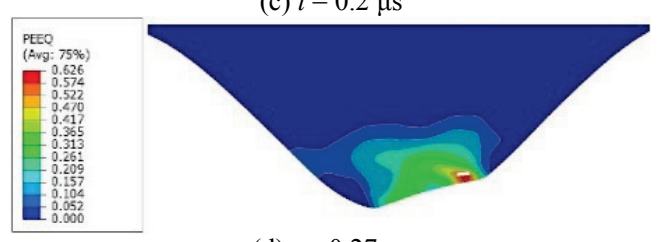

(d) $t=0.27 \mu \mathrm{s}$

Figure 9 Contour plots of the equivalent plastic strain of the asperity at different grinding moments, with shear strength of $k$

As seen from Fig. 7, when the shear strength is $0.2 k$, the value of the plastic strain at the initial moment is relatively small. The strain distribution after the contact shows favourable symmetry, and it evenly spreads along the contact centre with a semielliptical contact width. As the grinding proceeds, it takes the asperities longer wear time to reach the plastic deformation limit of the materials. This is because the interfacial shear strength of the contact surface in the model is relatively small, and the adhesion effects are relatively small. Relative grinding is prone to occur to the two interactive asperities, which produces relatively small work done by the external force. Accordingly, the time that the asperities wear and fail would be long.
As indicated by Fig. 8 and Fig. 9, when the interfacial shear strength increases to $0.8 k$ or $k$, under the influence of adhesion, the position of plastic strain caused by the resultant force of adhesive force and mechanical deformation force is close to the grinding interface that two rough solids make interactive contact. And it takes shorter time for the asperities to reach the plastic deformation limit of the materials. This is because the interfacial shear strength increases, the adhesive strength of the bonding points correspondingly increases. When the asperities reach the same grinding speed, the work done by external forces would increase, which makes the asperities enter the wear state earlier.

Thus, it is drawn that the larger the interfacial shear strength is, at the same grinding distance, the greater its equivalent plastic strain is. And the rough solid is more prone to wear and tear. The maximum point of plastic deformation determines the place of the first cracks, either on the surface or at a distance from the surface.

\subsection{Effects of the normal load on the equivalent plastic strain distribution}

Fig. 10 and Fig. 11 respectively represent the contour plots of the equivalent plastic strain before the wear of the asperity - No. 2 at different grinding moments under different normal loads.

As seen from Fig. 10 and Fig. 11, when the interfacial shear strength and the grinding speed stay constant, in the wear failure process of different normal loads, as the normal even-distributed load increases, the maximum plastic deformation of the asperity at the initial contact time tends to grow, which also determines an earlier occurrence time of the initial cracks. Since the difference between the applied normal loads is not large, the initial wear failure time is quite close.

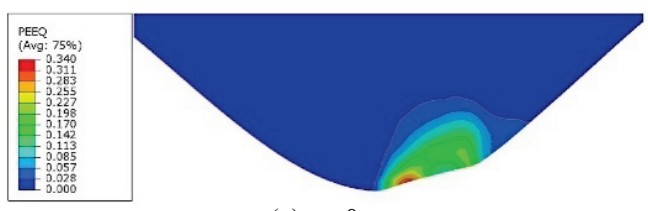

(a) $t=0 \mu \mathrm{s}$

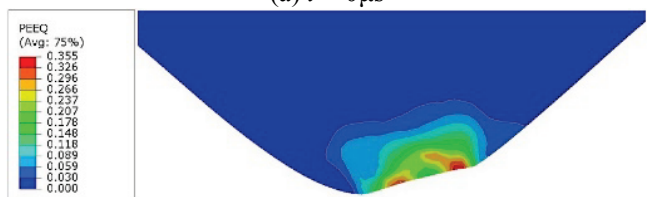

(b) $t=0.2 \mu \mathrm{s}$

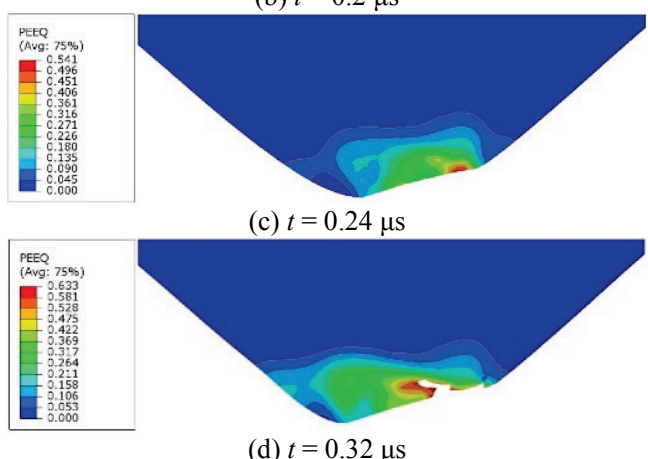

Figure 10 Contour plots of the equivalent plastic strain of the asperity at different grinding moments, with a normal load of $20 \mathrm{MPa}$ 

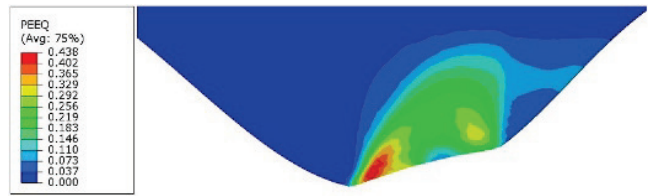

(a) $t=0 \mu \mathrm{s}$
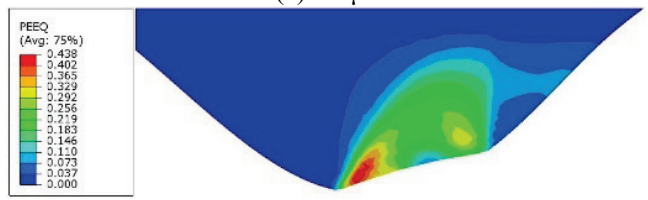

(b) $t=0.1 \mu \mathrm{s}$
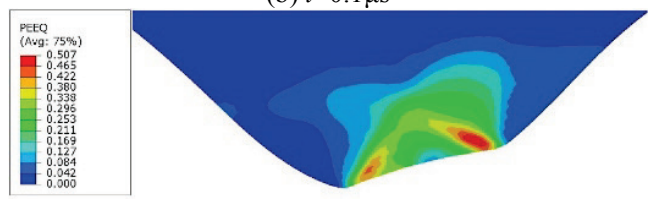

(c) $t=0.2 \mu \mathrm{s}$
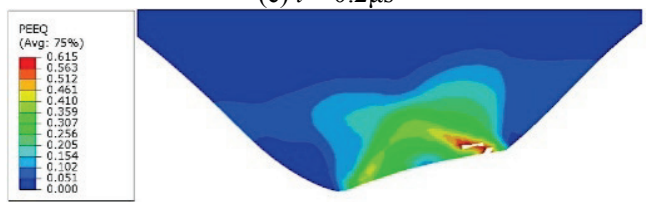

(d) $t=0.27 \mu \mathrm{s}$

Figure 11 Contour plots of the equivalent plastic strain of the asperity at different grinding moments, with a normal load of $60 \mathrm{MPa}$

\subsection{Effects of the grinding speed on the equivalent plastic strain distribution}

Fig. 12 and Fig. 13 are the equivalent plastic strain nephograms in the wear process of the asperity at different grinding speeds.

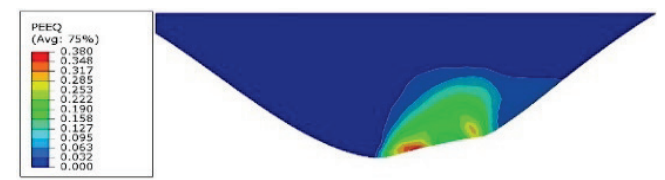

(a) $t=0 \mu \mathrm{s}$

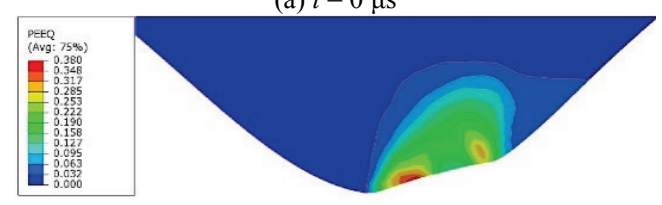

(b) $t=0.15 \mu \mathrm{s}$

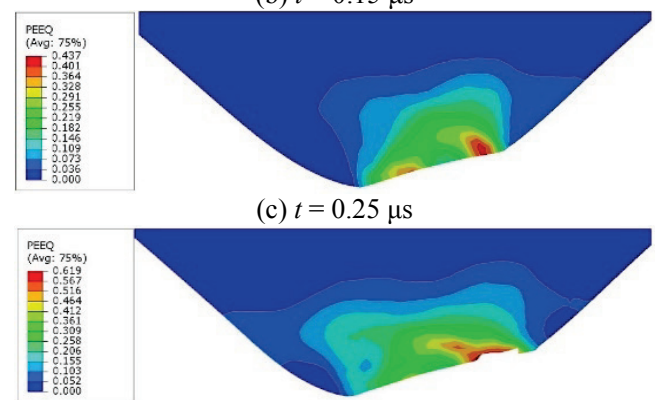

(d) $t=0.4 \mu \mathrm{s}$

Figure 12 Contour plots of the equivalent plastic strain of the asperity at different grinding moments, with a grinding speed of $20 \mathrm{~m} / \mathrm{s}$

As seen from Fig. 12 and Fig. 13, when the interfacial shear strength and the normal load stay unchanged, different grinding speeds make the asperity wear and tear at different sliding distances. When the grinding speed is relatively high, the distance where two interactively contacting asperities start to wear is longer, which is related to the deformation rate of the asperities in the grinding process.

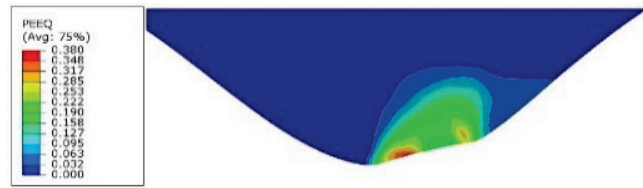

(a) $t=0 \mu \mathrm{s}$

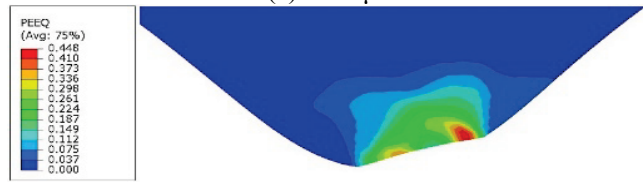

(b) $t=0.1 \mu \mathrm{s}$

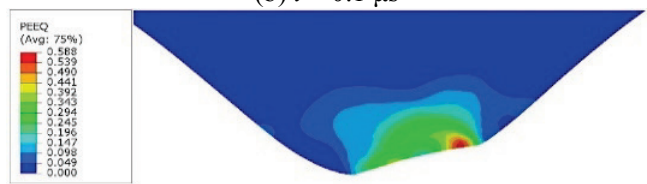

(c) $t=0.12 \mu \mathrm{s}$

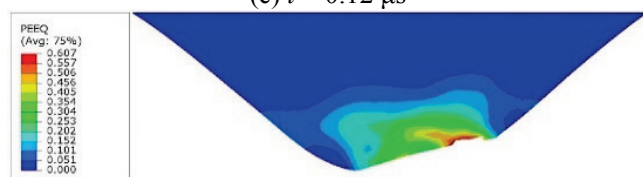

(d) $t=0.15 \mu \mathrm{s}$

Figure 13 Contour plots of the equivalent plastic strain of the asperity at different grinding moments, with a grinding speed of $60 \mathrm{~m} / \mathrm{s}$

\section{Conclusion}

This paper studies the frictional wear behaviour of the two-dimensional double rough surface grinding models under different states of the contact parameters. The surface structure parameters of the rough surface are determined according to the surface roughness of the friction auxiliary materials. Changes of different contact parameters are selected to conduct analysis of examples on the double rough surface grinding model. The study provides a foundation for the subsequent threedimensional model analysis, but also necessary theoretical basis to reveal the physical nature of wear. The following conclusions are drawn from the research results:

(1) The larger the interfacial shear strength is, at the same grinding distance, the greater its equivalent plastic strain is. The rough solids are more prone to wear and tear. The maximum point of the plastic deformation determines where the first cracks occur, either on the surface or at a certain distance below the surface (2). The greater the normal even-distributed load is, the greater the maximum plastic deformation of the micro-bulge at the initial contact moment is, which also determines an earlier occurrence time of the initial cracks. (3) When the grinding speed is relatively high, the distance where two interactively contacting asperities start to wear is longer.

\section{Acknowledgements}

This research is supported by National Natural Science Foundation of China (Grant No 51505241, Grant No 51175085), Natural Science Foundation of Fujian province (Grant No 2016J01227, 2017J01709). Young and Middle-aged Teachers Education Scientific Program of Fujian province (Grant No JA14329) and Science and 
Technology Project of Ningde city (20140203). Thanks to the support of Fujian Supercomputing Center.

\section{References}

[1] Yang, S. Z.; Wu, B. Trends in The Development of Advanced Manufacturing Technology. // Chinese Journal of Mechanical Engineering. 39, 10(2003), pp. 73-78. https://doi.org/10.3901/JME.2003.10.073

[2] Jamati, J.; Rooij, M. B.; Schipper, D. J. Plastic Deterministic Contact of Rough Surfaces. // ASME Journal of Tribology. 129, 4(2007), pp. 957-962. https://doi.org/10.1115/1.2768618

[3] Jackson, R. L.; Duvvuru, R. S.; Meghani, H.; Mahajan, M. An analysis of Elasto-plastic sliding Spherical Asperity Interaction. // Wear. 262, 1(2007), pp. 210-219. https://doi.org/10.1016/j.wear.2006.05.011

[4] Yin, X.; Komvopoulos, K. An Adhesive Wear Model of Fractal Surfaces in Normal Contact. // International Journal of Solids and Structures. 47, 7-8(2010), pp. 912-921. https://doi.org/10.1016/j.ijsolstr.2009.12.003

[5] Chen, G. A.; Ge, S. R.; Liu, J. L. Fractal Prediction Model of sliding Friction Force. // Journal of China University of Mining \& Technology. 29, 5(2000), pp. 492-495.

[6] Sahoo, P.; Chowdhury, S. K. R. A Fractal analysis of Adhesive Wear at the Contact between Rough Solids. // Wear. 253, 9(2002), pp. 924-934. https://doi.org/10.1016/S0043-1648(02)00243-0

[7] Yang, J.; Komvopoulos, K. A Mechanics Approach to Static Friction of Elastic-plastic Fractal Surfaces. // ASME Journal of Tribology. 127, 2(2005), pp. 315-324. https://doi.org/10.1115/1.1828080

[8] Majumdar, A.; Tien, C. L. Fractal Characterization and Simulation of Rough Surfaces. // Wear. 136, 2(1990), pp. 313-327. https://doi.org/10.1016/0043-1648(90)90154-3

[9] Huang, J. M.; Gao, C. H. Thermo-mechanical Research on Frictional Sliding between Elasto-plastic Rough Solid and Rigid Flat. // China Journal of Mechanical Engineering. 47, 11(2011), pp. 87-92.https://doi.org/10.3901/JME.2011.11.087

[10] Majumdar, A.; Bhushan, B. Role of Fractal Geometry in Roughness Characterization and Contact Mechanics of Surface. // ASME Journal of Tribology. 112, 2(1990), pp. 205-216. https://doi.org/10.1115/1.2920243

[11] Mandelbort, B.; Ness, V. Fractional Brownian Motions, Fractional Noises and Applications. // SIAM Review, 10, 4(1968), pp. 422-437. https://doi.org/10.1137/1010093

[12] Zahouani, H.; Vargiolu, R.; Loubet, J. L. Fractal Models of Surface Topography and Contact Mechanics. // Mathematical and Computer Modeling. 28, 4(1998), pp. 517-534. https://doi.org/10.1016/S0895-7177(98)00139-3

[13] Prasanta, S.; Niloy, G. Finite Element Contact analysis of Fractal Surfaces. // Journal of Physics D-Applied Physics. 40, 14(2007), pp. 4245-4252. https://doi.org/10.1088/0022-3727/40/14/021

[14] Zivic, F.; Babic, M.; Cvijovic-Alagic, I. el al. Wear Behaviour of Ti6Al4V Alloy against Al2O3 under Linear Reciprocating Sliding. // Journal of the Balkan Tribological Association. 17, 1(2011), pp. 27-36.

[15] Li, Y.; Li, Y. X.; Yang, M. S. el al. Analyzing the Thermal Mechanical Coupling of 40Cr Cold Roll-beating Forming Process based on the Johnson-cook Dynamic Constitutive Equation. // International Journal of Heat and Technology. 33, 3(2015), pp. 51-58. https://doi.org/10.18280/ijht.330307

[16] Mulvihill, D. M.; Kartal, M. E.; Nowell, D.; Hills, D. A. An Elastic Plastic Asperity Interaction Model for Sliding Friction. // Tribology International, 44, 12(2011), pp. 16791694. https://doi.org/10.1016/j.triboint.2011.06.018

\section{Authors' addresses}

\section{Lianfeng Lai}

corresponding author

Ningde Normal University, Department of Information, Mechanical and Electrical Engineering,

Ningde 352100, China

E-mail: lailianfeng82@163.com

\section{Chenhui Gao}

Fuzhou University,

Department of Mechanical Engineering and Automation, Fuzhou 350108, China

E-mail: gch@fzu.edu.cn

\section{Jianmeng Huang}

Fuzhou University,

Department of Mechanical Engineering and Automation, Fuzhou 350108, China

E-mail: huangjianmeng@fzu.edu.cn 